\title{
O JOGO DRAMÁTICO EM SUPERVISÃO: DO DESENVOLVIMENTO DO PAPEL DO PSICOTERAPEUTA AO PROCESSO PSICOTERAPÊUTICO DO PACIENTE
}

\author{
Maria Dulce Santiago de Carvalho ${ }^{1, *}$ (1)
}

\begin{abstract}
RESUMO
Da relação como pacienteemergem sentimentos, dúvidas, fantasias etemores que eventualmenteescapam do mundo interno de um terapeuta; são impasses que muitas vezes refletem bloqueios que limitam também a liberação da espontaneidade do paciente. O artigo coloca em pauta a supervisão com técnicas psicodramáticas como elemento na formação e no desenvolvimento do papel de terapeuta, relatando um estudo de caso no âmbito psicoterapêutico. O objetivo concentra em destacar o jogo dramático como possibilidade de reconhecimento de aspectos pessoais do supervisionando que interferem no processo psicoterapêutico e de manejo espontâneo-criativo de suas intervenções, integrando o conhecimento à dimensão vivencial. Foi possível concluir que a supervisionanda desenvolveu maior segurança no papel profissional, apontando ainda a significativa importância do supervisor nesse processo.
\end{abstract}

PALAVRAS-CHAVE: Psicodrama; Supervisão clínica; Jogos; Identidade profissional; Role playing.

\section{THE DRAMATIC GAME IN SUPERVISION: FROM THE DEVELOPMENT OF THE PSYCHOTHERAPIST'S ROLE TO THE PATIENT'S PSYCHOTHERAPEUTIC PROCESS}

\begin{abstract}
From the relationship with the patient emerge feelings, doubts, fantasies, and fears that eventually escape from the inner world of a therapist. These are obstacles that often reflect blockages and fears, which also limit the release of the patient's spontaneity. The article discusses the supervision with psychodramatic techniques as an element in the training and development of the therapist's role, reporting a case study in the psychotherapeutic scope. Its objective is to highlight the dramatic game as a possibility of recognizing personal aspects of the supervisee that interfere in the psychotherapeutic process and the spontaneouscreative strategy of his interventions, integrating knowledge to the experiential dimension. The study concluded that the supervisee felt professionally safer, also recognizing the significant importance of the supervisor in this process.
\end{abstract}

KEYWORDS: Psychodrama; Clinical supervision; Games; Professional identity; Role playing.

\section{ELJUEGO DRAMÁTICO EN SUPERVISIÓN: DEL DESARROLLO DEL ROL DEL PSICOTERAPEUTA AL PROCESO PSICOTERAPÉUTICO DEL PACIENTE}

\section{RESUMEN}

De la relación con el paciente surgen sentimientos, dudas, fantasías y miedos que acaban escapando del mundo interno del terapeuta; se tratan de impases que a menudo reflejan bloqueos que límite también la liberación de la espontaneidad del paciente. El artículo destaca la supervisión con técnicas psicodramáticas como elemento de formación y desarrollo del rol de terapeuta, reportando un caso de estudio en el ámbito psicoterapéutico. El objetivo se centra en destacar el juego dramático como posibilidad de reconocer aspectos personales del supervisado que interfieren en el proceso psicoterapéutico y en la gestión espontánea-creativa de sus intervenciones, integrando el conocimiento con la dimensión vivencial. Se pudo concluir que la supervisando desarrolló una mayor seguridad en su rol profesional, señalando también la gran importancia de la supervisora en este proceso.

PALABRAS CLAVE: Psicodrama; Supervisión clínica; Juegos; Identidad profesional; Juego de rol

1.Universidade Federal de São João del-Rei - São João del-Rei (MG), Brasil.

*Autora correspondente: mdulcesantiago@hotmail.com

Editora de seção: Rosely Cubo

Recebido: 15 Mar 2021 | Aceito: 10 Jun 2021 


\section{INTRODUÇÃO}

A supervisão de alunos ou mesmo de profissionais da área da psicoterapia assume significativa importância no cenário ensino-aprendizagem, no infindável processo de tornar-se um terapeuta, um vir-a-ser contínuo que se move em busca do novo e que, em contrapartida, o lança muitas vezes no escuro, para além de si mesmo, pondo-o diante de entraves e bloqueios que o paralisam, espantam a espontaneidade em suas condutas e limitam o poder criativo de suas intervenções. A super-visão amplia o olhar; permite que a luz se acenda e que o desequilíbrio desconcertante adquira sentido; articula teoria e prática, incluindo também uma terapia do papel. Nessa perspectiva, Calvente (2002) informa que são detectadas cenas pessoais do supervisionando que interferem no trabalho terapêutico, e, a partir de técnicas de dramatização, podem ser recriadas situações-problema, fazendo parte da aprendizagem do papel de terapeuta.

O presente estudo é fruto de uma supervisão decorrente de estágio obrigatório no âmbito psicoterapêutico, com enfoque fenomenológico-existencial e faz parte da construção do papel de psicodramatista didata supervisor. Trata-se de um estudo de caso, no qual foram utilizados técnicas e recursos psicodramáticos. A supervisionanda é uma aluna do último período de Psicologia da Universidade Federal de São João del-Rei (UFSJ). Ela não apresenta formação em Psicodrama, mas revela bastante interesse em conhecê-lo e aprofundá-lo posteriormente em sua prática profissional. A UFSJ não dispõe, em sua grade curricular, de disciplinas que abordem o psicodrama, ampliando entre discentes a demanda pelo trabalho com essa abordagem metodológica, de forma que partiu da própria aluna a solicitação pelo acompanhamento supervisionado do estágio.

O estudo apresentado teve como objetivos favorecer o encontro do psicoterapeuta consigo mesmo, de modo a promover seu encontro com o paciente e viabilizar o manejo espontâneo-criativo de suas intervenções, integrando o conhecimento à dimensão vivencial. Nesse sentido, teve como suporte metodológico Cukier (1992) e Calvente (2002), aprofundando nos jogos dramáticos e jogos de personagem, e adotou como referência: (a) o que acontece comigo diante desse paciente? e (b) o que acontece com esse paciente? A título de elucidação, no primeiro tópico são considerados e trabalhados os sentimentos e as sensações suscitadas no profissional - o eu comigo; e no segundo, encontram-se implicadas a dinâmica interna do paciente e as intervenções ou condutas do psicoterapeuta que podem ser mais apropriadas em determinado momento do processo terapêutico. Nesse contexto, Calvente (2002) preconiza que estar atento ao que se passa dentro de si ao atender aquele paciente é um pilar que consolida o desenvolvimento em supervisão de seu papel de terapeuta.

\section{Supervisor: um ser-com — Relação dialógica e super-visão em cena}

Ser terapeuta é ser-com-o paciente, é estar com ele, acolhê-lo em suas angústias e conflitos. Tendo essa perspectiva como norteadora da temática abordada e pesquisada, ser supervisor não deixa de ser diferente. Implica permitir que dúvidas e medos sejam compartilhados na construção do papel profissional, acolhendo e ressignificando sentimentos que podem interferir negativamente no adequado manejo do processo psicoterapêtico.

Nesse cenário, a relação com o supervisionando, sujeito existencial, constrói-se por meio do encontro e da tele, o que nos remete, respectivamente, a Buber (2001) e a Moreno (1975), permitindo a comunicação verdadeira entre as pessoas. Como a relação terapêutica envolve um encontro, ${ }^{1}$ a relação supervisor-supervisionando se configura também a partir de uma relação dialógica (Buber, 2001), marcada pelo verdadeiro interesse do primeiro em ajudar o segundo. De modo análogo, a espontaneidade e a criatividade acenam para um genuíno encontro existencial em um cenário no qual o supervisor se torna um ser-com o supervisionando; assim, o encontro deste consigo mesmo é uma via para o encontro com seu paciente.

1. "Um encontro de dois: olho a olho, cara a cara

E, quando estiveres perto, arrancarei teus olhos

e os colocarei no lugar dos meus,

e tu arrancarás meus olhos

e os colocarás no lugar dos teus,

então te olharei com teus olhos

e tu me olharás com os meus."(Moreno, 1975, p. 9) 
Ao identificar fundamentos fenomenológico-existenciais no pensamento de Moreno (1975), o terapeuta que mergulha nessa abordagem direciona-se a uma investigação da história de vida do paciente e suas particularidades, compreendendo-o em sua totalidade existencial. Com base na concepção fenomenólogico-existencial e articulando um diálogo com Moreno, Heidegger (2005) nos conduz a visualizar o homem como um ser-no-mundo, contextualizado que tem sua história e seu projeto de vida, que o tornam quem ele é. Almeida (2006) explica que o método exige do terapeuta uma atitude desprovida de ideias preconcebidas ou explicações psicológicas e científicas diante dos fenômenos, para que eles se mostrem por si mesmos. Nesses termos, o autor enfatiza: "apenas interrogo, ouço, vejo, percebo e sinto. Também me interrogo, me ouço, me vejo, me percebo e me sinto; diante das informações desse mundo que chegam a mim, entedio-me, alegro-me, emociono-me”. (Almeida, 2006, p. 42). Para Almeida (2006), ao utilizar o método fenomenológico-existencial, o terapeuta se entrega à intuição criadora, abre-se à relação intersubjetiva, utilizando a intencionalidade para integrar-se ao universo que está apreendendo. E aponta "procuro um estado télico" (Almeida, 2006, p. 42). Tomando essas ideias como referência, o supervisionando é percebido como um ser existencial, que carrega sua vivência, e esta pode evocar sentimentos em sua relação com seu paciente. Em meio ao desenvolvimento do papel profissional, a supervisão desponta remontando fatos do passado e do presente, trazendo também em seu bojo cenas terapêuticas desafiadoras que são reencenadas e que proporcionaram uma nova experiência.

Para além desse contexto, o supervisionando necessita ter um amplo conhecimento da dinâmica interna de seu paciente, sua maneira de pensar e agir, refletindo um genuíno entendimento daquela pessoa à sua frente, para que assim busque uma relação verdadeira em sua ação e criação com ele; encontra-se estritamente vinculado à própria percepção como sujeito existencial e sua apreensão do paciente como um ser-no-mundo.

\section{Dos entraves no caminho à busca da supervisão}

O paciente quer fazer terapia; o terapeuta deseja ajudá-lo, mas não sabe ou está perdido na condução das sessões, talvez por falta do poder espontâneo-criativo em suas ações diante daquele que se encontra com ele, ou porque o paciente se depara com a dificuldade em se expressar ou de trazer algum assunto para ser trabalhado em terapia.

Em meio a esse cenário, exige-se muitas vezes do profissional uma atitude de sabe-tudo, transportando-o para o lugar daquele que tudo-resolve; uma vez que as expectativas se confrontam (o que se busca e o que posso oferecer), ele esbarra em questões que invocam sua vulnerabilidade. Seu incômodo diante do não saber o que fazer com aquele determinado paciente o leva muitas vezes a questionar sua competência, conduzindo-o a reflexões e devaneios de como seria a conduta de outro terapeuta se estivesse em seu lugar. Entram em sua cena imaginária seus grandes mestres psicodramáticos, ícones com superpoderes que sempre sabem o que fazer e como trabalhar ou dramatizar com seus pacientes; pelo menos é o que ele acredita... E assim ele se encontra em meio a seus solilóquios: "devo ser incompetente mesmo, não consigo avançar com esse paciente...”.

Vasconcellos (2007) aponta que, diante de situações em que o profissional se vê perdido ou emperrado com seu paciente e teme perder o controle, colocar para ele seus incômodos — os sentimentos e as emoções suscitados nele, terapeuta pode ajudar. A autora explica que o problema do paciente de entrar em contato com suas questões pode ser sentido como dificuldade de conduzir a sessão com o intuito de ajudá-lo.

A supervisão entra em cena como um elemento valioso na formação profissional; dividir as dúvidas e as angústias com o supervisor e os colegas de grupo ajuda o supervisionando a aprender a separar as questões que são do paciente daquilo que é dele, uma vez que não se está isento de esbarrar em questões pessoais não resolvidas. Em termos psicodramáticos, Amato (2002) menciona que no palco existe também outra cena que não é apenas a do paciente — a cena do próprio psicodramatista/diretor.

A supervisão em psicodrama é o palco para o errar-acertar, conhecer-se e reconhecer-se, criar-recriar e, nesse sentido, ilimitar as possibilidades de manejo terapêutico. Por meio do caráter espontâneo-criativo conferido ao método psicodramático, o diretor, que representa a figura do produtor da encenação e tem como função estimular a espontaneidade, mantém o supervisionando aquecido para a ação e amplia, por meio das cenas, sua visão sobre as questões suscitadas. Ao quebrar a 
hierarquia que muitas vezes é acentuada, este se percebe no mesmo patamar de seu supervisor, construindo de modo espontâneo seu estilo de terapeuta.

Nesse percurso, Bucher (1989) e Lazzarini, Viana e Veludo (2008) consideram que a relação pedagógica visa à emancipação e não à conservação da hierarquia que separa professor e aluno. A partir do papel do primeiro, aludimos à concepção de que ensinar é muito mais do que a transmissão de conteúdos; envolve o contínuo aprendizado, englobando a cocriação e a transformação pela ação. De modo análogo, deve-se ocorrer o mesmo em um trabalho de supervisão. Barros (2017) aponta que este consiste em um espaço de aprendizagem, e ser supervisor implica "entrar em outra concepção de poder - o poder do encontro, da centelha divina que vive, convive, se trata e se transforma por meio das relações" (p. 35). Do seu lugar, o supervisionando sente que não está sozinho e é conduzido a fazer seus solilóquios, montando seus dramas, externalizando seus temores e se permitindo ousar no processo com o paciente.

Lazzarini et al. (2008, p. 123) comentam que "um aspecto da supervisão consiste em compreender a relação terapeuta-paciente pela relação supervisor-supervisionando", entendendo que ambos devem caminhar juntos na análise sobre a atuação e as intervenções a serem feitas. Tendo como norteadoras as ideias expostas, Calvente (2002) também salienta que, na supervisão, o aluno tem a possibilidade de fazer dialogar teoria e prática, constituindo uma matriz de aprendizagem e possibilitando vivenciar o papel profissional. Segundo o autor, a supervisão representa um espaço de aprofundamento e ampliação de conceitos à luz do material clínico com o qual se está trabalhando.

Paralelamente, Barros (2017) esclarece que a função do supervisor é estimular a prática, oferecendo articulações com a teoria e reflexões para a coerência da aplicação do método. Uma vez identificadas as dificuldades e os impasses do supervisionando na condução das sessões, o supervisor necessita ser cauteloso em suas orientações e condutas para não reforçar bloqueios e fraquezas, lançando este ainda mais num abismo ou no escuro. Nesse percurso ele sustenta em si, ou presume-se que deve carregar, a sutileza de iluminar o caminho. Ele ajuda a construir a ponte para um efetivo aprendizado do papel de terapeuta. O que se espera desse profissional é uma atitude de facilitação, auxiliando o supervisionando no estabelecimento de condições adequadas para o manejo de situações e cenas que emergem na relação com o paciente.

A supervisão oferece o aspecto vivencial; ancorada nos pressupostos morenianos ao lançar mão das técnicas psicodramáticas, a supervisão se constitui como um pilar na construção do papel profissional de terapeuta, somado ao conhecimento teórico e ao processo psicoterapêutico (Calvente, 2002).

Ao longo das sessões de supervisão são utilizados vários recursos, em que ganham destaque as vivências, os jogos e as técnicas psicodramáticas, lançando o supervisionando no "como se", ampliando as possibilidades de atuação e conduzindo-o a visualizar o processo terapêutico de seu paciente. Para além das cenas trazidas ao palco, Lazzarini et al. (2004) aponta que todo o arsenal vivencial associado com o compartilhamento de emoções e sentimentos provoca também uma ampliação do conhecimento de si mesmo, favorecendo uma melhor compreensão de sua identidade profissional.

Notadamente, o cenário lúdico permite estar do outro lado - lugar do paciente favorecendo maior percepção deste - e paralelamente amplia a apreensão do próprio papel de terapeuta. Em termos de experimentação de papéis, a dramatização é apontada como uma atividade frequentemente utilizada na supervisão psicodramática (Hannes \& Fürst, 2013), incluindo também várias técnicas de ação, como a reencenação de uma cena terapêutica, o role playing e a utilização de técnicas psicodramáticas como a inversão de papéis (trocar de papel com seu paciente), o espelho (representar para o supervisionando sua maneira de ser ou agir na relação com o paciente, para que ele possa se ver e se perceber), o duplo (falar algo que não está claro para o supervisionando), além de trabalhar com esculturas (criar uma imagem da relação com o paciente ou de aspectos dele, com o objetivo de ampliar sua percepção e seu entendimento sobre ele). Calvente (2002), da mesma forma, enfatiza a utilização do role playing, em que o supervisionando ocupa o lugar de seu paciente e investe no uso das técnicas dramáticas como um meio de diminuir a ansiedade como terapeuta e desenvolver maior segurança no papel.

Dando continuidade às possibilidades de supervisão, no mesmo enfoque, encontram-se os jogos dramáticos. As supervisões que integram o acompanhamento na temática desenvolvida englobam jogos e técnicas dramáticas que 
auxiliam o supervisionando a se assumir diante do paciente, despertando seu potencial ativo e criativo por meio de ferramentas e instrumentos metodológicos e psicodramáticos e de vivências, conduzindo-o ao conhecimento de si mesmo e à maior percepção do próprio papel profissional. Em meio às descobertas pelo caminho, o supervisionando é provocado a detectar cenas de seu mundo interno ligadas à própria história, que possam estar interferindo no trabalho terapêutico com seu paciente. A partir de recursos psicodramáticos nos quais o jogo dramático e o role playing se inserem, o supervisor caminha junto, iluminando o caminho.

\section{O jogo dramático e o role playing}

O jogo dramático é um recurso extremamente valioso do psicodrama, que possibilita, por meio da improvisação, a reprodução de situações vividas ou imaginadas; no cenário da supervisão, o jogo auxilia o supervisionando a perceber suas condutas, (re)conhecer-se e vislumbrar novos caminhos à sua frente.

Motta (2002) considera que, nesse tipo de jogo, a criação está ancorada no lúdico, no qual o role playing abre para o homem uma nova dimensão da existência em que predomina a liberdade. O ousar libera o indivíduo para se permitir, invocando as múltiplas possibilidades de experimentar a vida. De forma complementar, Datner (1995) expressa que "o jogo dramático tem como núcleo vivenciar o jogo assumindo personagens em permanente caráter lúdico” (p. 86). São levadas ao cenário dramático as dinâmicas interpessoais, favorecendo a expressão de sentimentos, emoções e sensações; no âmbito da supervisão, o supervisionando é estimulado a adotar novas atitudes, outros movimentos, resgatando o arriscar-se e o ousar na possibilidade de experimentar o novo.

No jogo, é possível viver quase tudo. Personagens são criados, limitações são compensadas e impasses são resolvidos. Castanho (1990) afirma que o jogo dramático envolve os participantes, emocionalmente, na atividade de expressar as criações de seu mundo interno, e ressalta que "o personagem criado guarda uma relação metafórica com algum aspecto da dinâmica interna do indivíduo” (p. 34). Nesse aspecto, o supervisionando acessa aspectos pessoais, vivenciando-os de modo lúdico e transformador para si, o que, por consequência, repercutirá positivamente no processo com o paciente.

Na visão de Conceição (2012), a pessoa pode deslocar o que viveu para sua realidade e, assim, encontrar respostas para seus conflitos, angústias ou dúvidas. Desse modo, ao supervisionando é facilitada a transposição do aprendizado vivenciado no aqui e agora da supervisão para o aqui e agora com o paciente na sessão.

Nesse campo de argumentações, Calvente (2002) explica que o supervisionando transita pela tomada de papel (role taking), pelo desempenho do papel (role playing) e pela criação do papel (role creating), diferindo-se do role training, que, por meio do treino, reforça papéis predeterminados, moldando muitas vezes o sujeito e bloqueando a espontaneidade e a criatividade, conforme a ideia desenvolvida por Moreno. O primeiro se refere à adoção de um papel acabado e estabelecido; é o papel inicial que o supervisionando assume, dirigindo-se ao role playing, ao jogar com mais liberdade seu papel de terapeuta no "como se", por meio da dramatização, até alcançar o role creating, implicando a criação do papel. A tônica aqui incide na coparticipação do supervisor, de tal forma que o supervisionando criará o próprio estilo de ser terapeuta.

Quando o estudante se sente identificado com seu papel, pode representá-lo com espontaneidade e vivenciá-lo de modo integrado com o restante de sua pessoa, o que lhe permite desempenhá-lo com estilo próprio e com uma quantidade cada vez menor de ansiedade. Seguindo a ideia moreniana, quanto menor a ansiedade, maior a espontaneidade e a criatividade e vice-versa. (Calvente, 2002, p. 113).

A supervisão psicodramática pelo role playing possibilita explorar os vários desdobramentos e as consequências dos comportamentos vivenciados por ele próprio e pelo paciente, aliviando tensões e oferecendo novas respostas e aprendizados para a situação vivenciada, libertando-o de uma situação paralisante. No “como se”, o supervisionando saboreia seu papel de terapeuta e experimenta também o contrapapel - o papel de seu paciente. 


\section{Aquecendo-se e aquecendo o paciente}

A partir do método psicodramático, a supervisionanda, que chamaremos de Simone ${ }^{2}$, foi orientada quanto à significativa importância do warming up no processo psicoterapêutico — o que lança o paciente na ação espontânea e criativa. Enfatizamos não apenas aquele que envolve sua preparação para trabalhar suas questões e seus conflitos, mas essencialmente o próprio aquecimento da supervisionanda no papel de terapeuta, para conduzir a sessão de modo mais fluido, despertando-o para um livre desempenho de papéis. Nesse aspecto, Calvente (2002) aponta que é ele que prepara para ação, o que faz surgir a espontaneidade, fazendo a junção do pensar e do sentir, evitando a atuação — uma mera atuação superficial.

Moreno destaca que "a espontaneidade do diretor é o que aquece o paciente" (Cukier, 2007, p. 167). O terapeuta precisa alavancar meios de se manter aquecido durante todo o processo dramático, porque a falta de estimulação pode ter implicação no desenrolar das cenas e no manejo adequado das técnicas psicodramáticas. Como afirma Amato (2002, p. 73), "Com certeza, ao aquecimento do protagonista se justapõe o aquecimento do diretor e do ego auxiliar".

Durante as supervisões, o aquecimento da supervisionanda assumiu grande destaque, uma vez que seus solilóquios revelavam desânimo na relação psicoterapêutica, e a técnica do espelho pôde fazê-la conscientizar-se desse fato. Diante de suas dificuldades iniciais, relativas ao que fazer com o que seu paciente verbalizava — uma vez que ele contava com satisfação suas atitudes, que causavam nela certa indignação, e não deixava clara sua demanda por terapia —, Simone comentou que já torcia até mesmo para que ele não comparecesse à sessão. Foi-lhe sugerido que buscasse dentro de si elementos que pudessem contribuir para estar mais disponível e aquecida para trabalhar com ele. Simone passou a ativar os iniciadores corporais antes mesmo das sessões (alongava o corpo, pulava, cantava e dançava trechos de sua música preferida), passando a sentir-se mais aberta para estar com ele e entrar em seu mundo.

Ainda, como parte integrante da supervisão, foram-lhe indicadas leituras embasadas na compreensão fenomenológicoexistencial e na abordagem e metodologia psicodramáticas, que permitiram aprofundar os estudos e ampliar os conceitos à luz do caso clínico que estava sendo supervisionado.

\section{DISCUSSÃO E ANÁLISE DOS RESULTADOS}

Ao longo da trajetória em que se estendeu o processo de supervisão, enfatizava-se que apreender as técnicas psicodramáticas implicava alinhar a teoria do psicodrama com a prática. Por meio de seus recursos lúdicos, a chama existente no supervisionando é despertada conforme suas potencialidades, e a partir da espontaneidade, é possível adequar uma resposta nova, emergindo a criatividade do papel profissional.

Nesse percurso, lançamos mão de vários jogos dramáticos, atentos à intrínseca relação destes com o embasamento e os objetivos terapêuticos que iam tomando forma e delineavam os caminhos pela frente.

\section{A utilização do jogo dramático em supervisão}

A seguir, é descrita e elucidada a aplicabilidade do jogo no contexto da formação psicoterapêutica. No cenário do desenvolvimento do papel profissional, a partir da reflexão dos próprios sentimentos, a supervisionanda apreende novas maneiras de ser-com seu paciente, sendo convocada a ousar e penetrando no universo lúdico do como se.

\section{O jogo do personagem}

A partir das falas de Simone relativas à vontade de desistir, motivadas pelo fato de o paciente apresentar-se difícil (sic) e inacessível (valores morais contrários à sociedade, mentiras e baixa empatia, sugerindo indiferença aos outros) e de que

2. Nome fictício para preservar sua identidade. 
ela não conseguia avançar com ele, a supervisionanda foi convidada a se movimentar pela sala, a fim de aquecer-se para aprofundar nas questões que a afligiam. Solilóquios foram feitos e foi-lhe solicitado que deixasse que emergissem imagens envolvendo seu futuro profissional e a relação com sua profissão. Relatamos a seguir, de modo sucinto, um fragmento que ilustra um jogo dramático realizado no intuito de trabalhar questões oriundas de sua vida pessoal, que pudesse estar dificultando o prosseguimento das sessões. Utilizando-se a princípio de um aquecimento de um psicodrama interno, a supervisora a convidou para viajar para dentro de si e imaginar um palco, deixando as cortinas abrirem e permitindo fluir as cenas que surgissem (paulatinamente e em tom de voz brando/tranquilo). Em seguida, foi estimulada a entrar em contato com seus sentimentos, despertando espontaneamente um personagem, deixando-o emergir, representando essas imagens e sensações que estava sentindo. Voltados para "o que acontece comigo com esse paciente", a ideia era conectá-la com seu mundo interno buscando investigar qual personagem carregava as emoções e os sentimentos que ela estava vivenciando com esse paciente e que também expressava emoções que se referiam à sua história de vida.

Assim que Simone acessou esse personagem, ela respondeu: “Curupira! Isso, um curupira!”. O diálogo segue:

Supervisora: "Eu quero conhecer esse personagem. Vá entrando no papel desse personagem, deixe ele vir à tona... respire... Quem é você? O que você faz?".

Simone: "Eu olho para a frente e ando para trás... um olho lá, um pé cá...".

Supervisora: "Como é isso? Olhar... andar?".

Simone: "Quero avançar, mas me sinto impotente, acho que não dou conta... Estou atenta, preparada... sei de tudo, mas meus pés não me deixam ir... Não saio do lugar, não sei andar com meus próprios pés.".

Supervisora: “Ok! Faz tempo que você faz isso, Curupira? Quando você surgiu na vida de Simone?".

[A supervisora mantém-se incentivando Simone.]

Simone: "Sim, acho que desde sempre...".

Supervisora: "Ok... respire fundo, visualize uma cena em que esse personagem surgiu, se faz presente. Lembre-se de uma cena, traga uma lembrança onde ele te acompanha, onde isso acontece."

[A supervisora investiga o maior número possível de detalhes e informações.]

Simone: Desde criança, mas... [Faz uma pausa e respira.] Lembro de uma viagem em que todas as minhas amigas foram. Eu queria muito ir, muito mesmo, mas meus pais me colocaram tanto medo de que eu não iria conseguir me virar que acabei não indo... Eu tinha 19 anos.".

Supervisora: "O que você sentiu?".

Simone: "É o querer, mas não fazer... Meus pais sempre me protegeram; nunca andei com minhas próprias pernas. Eles decidiam por mim. Aprendi a ser insegura.".

A supervisora explorou com a supervisionanda suas lembranças e seus sentimentos e utilizou a técnica da inversão de papéis, designando uma almofada para ser o Curupira e estabelecendo um diálogo entre os dois, no qual Simone verbalizou muita emoção, dizendo para o Curupira o que ele estava fazendo com ela e, ao mesmo tempo, ouvindo dele também. A interação seguiu até finalizar questionando-a o que precisava naquele momento para não ter que criar esse personagem. A resposta foi: "coragem para correr riscos", e a supervisora fez um duplo: "com medo das derrotas não saboreio as vitórias", ao que a supervisionanda consentiu com a cabeça, revelando-se radiante e sorridente. Outros conteúdos também vieram à tona e, dentre eles, ela pôde perceber como questões envolvendo sua sexualidade também estavam esbarrando no campo da sexualidade do paciente, provocando bloqueios na relação terapêutica.

Posteriormente, a supervisora voltou à lembrança que emergiu, recriando a cena da viagem não realizada, e apontou para a supervisionanda: "Como você gostaria de terminar essa cena?". Ela refaz a cena, tomando a decisão de acompanhar as amigas na viagem; mesmo com certos problemas que colocou na encenação (comida, roupa), ela conseguiu superar e curtir a viagem. Ao finalizar a supervisão, tendo o jogo dramático como deflagrador de aspectos significativos da história da supervisionanda, ela se deu conta de como o medo de tomar suas decisões, assumir riscos por suas escolhas e considerar-se incapaz refletia em outros setores de sua vida, sobretudo no lado profissional, na relação que estabelecia com seu paciente. 
Esse jogo dramático ilustra o trabalho em supervisão de questões da própria supervisionanda consigo, com o objetivo de distinguir o que faz parte dela e de seu mundo e que interfere nas cenas do paciente e invade o espaço terapêutico. Dando visibilidade a essa questão, é importante salientar que o supervisor deve ter cuidado para não transformar o espaço de supervisão em psicoterapia, estabelecendo e aprofundando um vínculo psicoterapêutico com o supervisionando (Lazzarini et al., 2008). Assim como Calvente (2002), acreditamos que a terapia do papel é parte fundamental da supervisão, clarificando pontos essenciais para o aluno ou o profissional quanto às situações vivenciadas por ele, sem, no entanto, descartar o próprio processo terapêutico da supervisionanda.

\section{Jogo: As partes do meu todo}

Simone informa que, com grande frequência, Rogério ${ }^{3}$ trazia para a sessão a questão de "ser manipulador" (expressão trabalhada no processo psicoterapêutico com ele) para indicar que ele usava estratégias para conseguir o que queria das pessoas e de situações. Ela não conseguia identificar a demanda de Rogério por terapia (ela não conseguia perceber coerência entre o que seu paciente dizia e o que gostaria de alcançar com seu processo terapêutico, fazendo-a questionar o que o mantinha nesse espaço, uma vez que permanecia do mesmo jeito). Incomodada com a estagnação em que ele se encontrava, a supervisora sugeriu que a supervisionanda propusesse um jogo dramático. Partindo de suas percepções, Simone apontou para Rogério como em muitos momentos ele consegue manipular as pessoas e as situações ao seu redor e propôs um jogo (átomo social), que teve como consigna inicial: "Utilizando os objetos aqui do consultório [Simone mostra uma caixa com diversos objetos, almofadas e miniaturas], escolha um para representar você e outros para representar o seu mundo, a sua vida, o que faz parte dela".

Rogério escolheu um relógio de mesa para ser ele; uma caneta grande colorida para representar a namorada (não sabe se gosta dela; acha que pode ser uma amizade colorida; ela quebra os galhos dele com os trabalhos na faculdade, é estudiosa); uma flor para ser a irmã (frágil e dependente); uma espada para ser o cunhado; uma pelúcia para ser a mãe; uma caderneta para representar a faculdade; e um coração de pelúcia para ser sua paixão por jogos eletrônicos.

Ele se viu no meio de todos esses relacionamentos e se colocou no lugar de cada um (por meio de entrevista no papel) e inverteu de papel com todos eles. No final da sessão, Rogério compartilhou com Simone como sua vida era um vazio, percebeu-se solitário. Quanto mais se gabava de manipulá-los, mais isso o jogava na solidão, numa tentativa desesperada de se sentir e de se fazer importante. Soltou-se no sofá e expressou que se sentia um nada. A supervisionanda e seu paciente puderam conversar sobre a responsabilidade dele naquilo de que ele se queixava e as implicações que isso traria caso se mantivesse no mesmo lugar.

A partir dessa sessão, o processo terapêutico tomou um novo rumo e ambos se sentiram mais à vontade para um trabalho conjunto, que envolvia o terapeuta em ser-com-o-paciente.

Em vista a essas proposições, os dados discutidos a partir dos fragmentos exemplificados apontam a utilização do jogo dramático em supervisão como possibilidade de reconhecimento de aspectos pessoais do supervisionando que interferiam no processo psicoterapêutico, bem como permitiu um manejo mais espontâneo-criativo de suas intervenções, integrando o conhecimento à dimensão vivencial.

Na visão de Perazzo (2010), a supervisão com referencial teórico-metodológico psicodramático bem conduzida constitui-se como uma ponte que une teoria e prática e revestimento pessoal, fluindo a partir da espontaneidade e da criatividade do psicodramatista. Nesse parâmetro, o autor reforça o sentido de estar junto, compartilhar e acolher, guiando ao que ele entende como movimento múltiplo de liberação existencial.

\section{CONSIDERAÇÕES FINAIS}

A supervisão oferece técnicas psicodramáticas ao aluno ou ao profissional da área da psicoterapia que procura a possibilidade de realizar conexões com seu mundo interno e com o de seu paciente, trazendo à tona a espontaneidade e a criatividade perdidas e resgatando a relação consigo mesmo no papel de terapeuta. Nesse percurso, o jogo dramático se

3. Nome fictício para designar o paciente. 
insere na supervisão psicodramática, alicerçada nos fundamentos teórico-metodológicos do psicodrama como um meio de desenvolver o papel profissional da supervisionanda, estimulando-a a participar ativamente do material que traz para a supervisão, deslocando-a para o aspecto vivencial e fazendo uma junção entre o conhecimento teórico, a abordagem e o método psicodramático.

Por meio de sua metodologia valiosa, o psicodrama estende o jogo e as técnicas dramáticas ao contexto da supervisão, revelando-a como uma ponte que conduz ao aprofundamento de conceitos e ao desenvolvimento das competências técnicas necessárias ao papel profissional.

Estreitamente vinculado à formação do papel de terapeuta, o estudo apresentado também envolveu experiências que integraram a construção do papel de psicodramatista didata supervisor, uma aprendizagem e um crescimento constantes, que compartilha práticas e contribui para o desenvolvimento do terapeuta-diretor, abrindo o caminho para um encontro.

Nesse cenário, o supervisor se destaca como um ser-com (o supervisionando), caminhando ao seu lado e procurando ver com os olhos dele seu paciente, pela representação e pelas técnicas dramáticas, conduzindo-o ao seu desenvolvimento criativo como terapeuta. E não é de se espantar que, nesse caminho, o próprio supervisor também possa aprender e se reinventar em sua prática profissional.

\section{DISPONIBILIDADE DE DADOS DE PESQUISA}

Não se aplica.

\section{FINANCIAMENTO}

Não se aplica.

\section{AGRADECIMENTOS}

Gratidão ao IMPSI, Federada do qual faço parte, especialmente à pessoa da Graça, grande mestra, fundamental na minha formação como psicodramatista didata, terapeuta de aluno e supervisora, sendo este artigo fruto desse aprendizado.

\section{REFERÊNCIAS}

Almeida, W. C. (2006). Psicoterapia aberta: O método do psicodrama, a fenomenologia e a psicanálise. Ágora.

Amato, M. A. (2002). A poética do psicodrama: O grupo autodirigido e a dinâmica da cena. Aleph.

Barros, L. M. S. (2017). Supervisão socioeducacional: Compartilhando a construção do papel de supervisor em psicodrama. Revista Brasileira de Psicodrama, 25(2), 28-36. https://doi.org/10.15329/2318-0498.20170019

Buber, M. (2001). Eu e tu. (N. A. Von Zuben, Introd. e Trad.). Centauro.

Bucher, R. E. (1989). A psicoterapia pela fala: Fundamentos, princípios, questionamentos. EPU.

Calvente, C. (2002). O personagem na psicoterapia: Articulaçôes psicodramáticas. Ágora.

Castanho, G. P. (1990). O jogo dramático na formação do psicodramatista. Revista da FEBRAP, 310-329.

Conceição, M. I. G. (2012). Jogos Dramáticos. In M. P. Nery, \& M. I. G. Conceição (Orgs.), Intervenções grupais: O psicodrama e seus métodos (pp. 145-159). Ágora.

Cukier, R. (1992). Psicodrama bipessoal: Sua técnica, seu terapeuta e seu paciente. Ágora.

Cukier, R. (2007). Para uma dramatização bem-sucedida. In M. C. M Vasconcellos (Org.), Quando a Psicoterapia trava (pp. 157-178). Ágora.

Datner, Y. B. (1995). Jogando e aprendendo a viver. In J. C. Motta (Org.), O jogo no Psicodrama (2a ed., pp. 85-95). Ágora. 
Hannes, K., \& Fürst,J. (2013). Psicodrama na supervisão de alunos em formação: Impacto na aplicação de intervenções verbais e dramatização na aprendizagem. Revista Brasileira de Psicodrama, 21(2), 117-132.

Heidegger, M. (2005). Ser e tempo (Parte I, 15ª ed., M. S. C. Schuback, Trad.). Vozes.

Lazzarini, E. R. et al. (2004). A supervisão didática no contexto da formação psicoterapêutica. Temas em Psicologia da $S B P, 12(1), 18-27$.

Lazzarini, E. R., Viana, T. de C., \& Veludo, C. M. B. (2008). A supervisão na formação do psicoterapeuta. Revista Brasileira de Psicodrama, 16(1), 121-129.

Moreno, J. L. (1975). Psicodrama (A. Cabral, Trad.). Cultrix.

Motta, J. C. (2002). Jogos: Repetição ou criação? Abordagem psicodramática. Ágora.

Perazzo, S. (2010). Psicodrama: O forro e o avesso. Ágora.

Vasconcellos, M. da C. M. (Org). (2007). Quando a psicoterapia trava. Ágora. 